
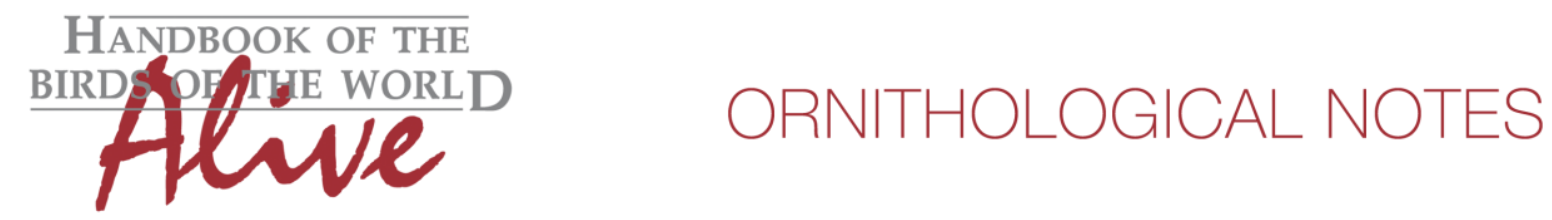

\title{
Notes on the vocalizations of Creamy-breasted Canastero (Asthenes dorbignyi)
}

Peter Boesman

In the following we briefly analyze and compare voice of the different races of Creamybreasted Canastero (Asthenes dorbignyi). We also try to quantify the extent of any vocal differences using the criteria proposed by Tobias et al. (2010), as a support for taxonomic review. We have made use of sound recordings available on-line from Xeno Canto (XC).

Song comparison of different races is somewhat hampered by the fact that there seems to be confusion about the exact boundaries of dorbigny/consobrina and consobrina/arequipae. Also, voice variation is such that it is not straightforward to set aside wrongly identified recordings, which may further negatively affect preciseness of measured data.

We have only compared songs, as few recordings of call notes are available.

A.d.dorbignyi ( $\mathrm{n}=6$, only recordings taken from Argentina and S Bolivia)

Song is either a series of well spaced notes gradually accelerating into a descending trill (Fig. 1), or simply a trill. In both cases, there can be sudden changes in note shape and related pace during the trill. At the end the trill always slows down while fading and decreasing in pitch. Sometimes two birds may utter a trill in response to one another, then one trill lower or higher pitched than the other.

There is quite some variation among the recordings, and we thus have to limit us to some general parameters:

length of full song

highest center freq.

shortest note

shortest pause

longest note

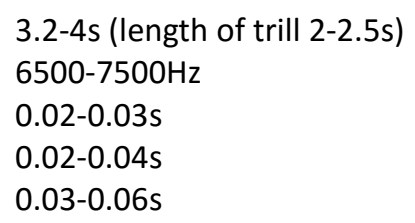

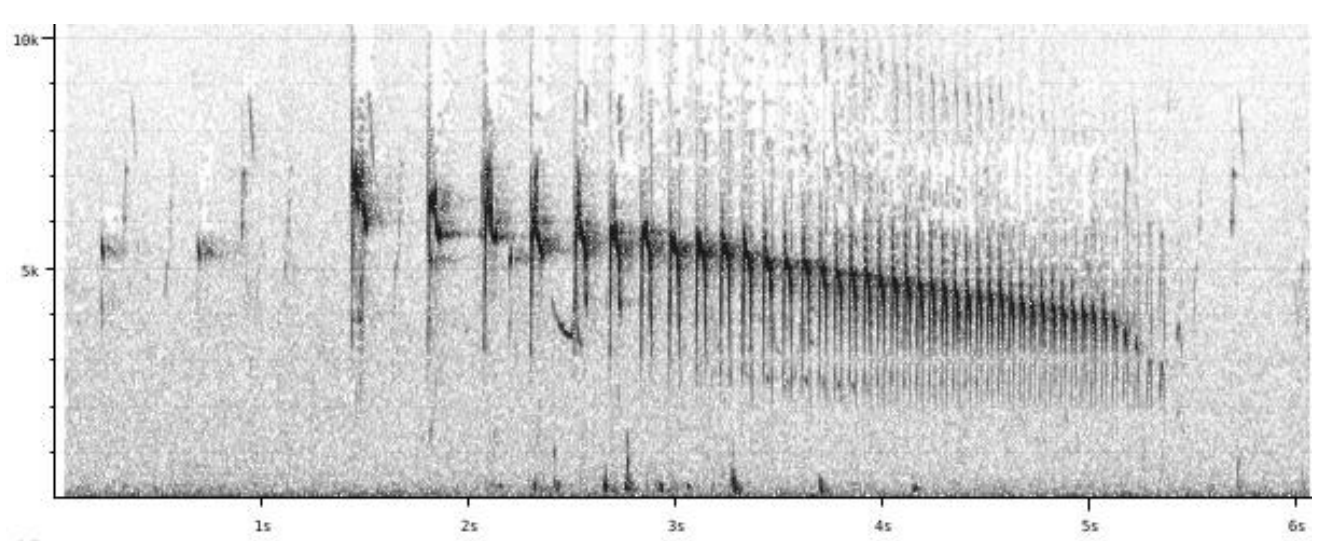

Figure 1: long song of dorbignyi 

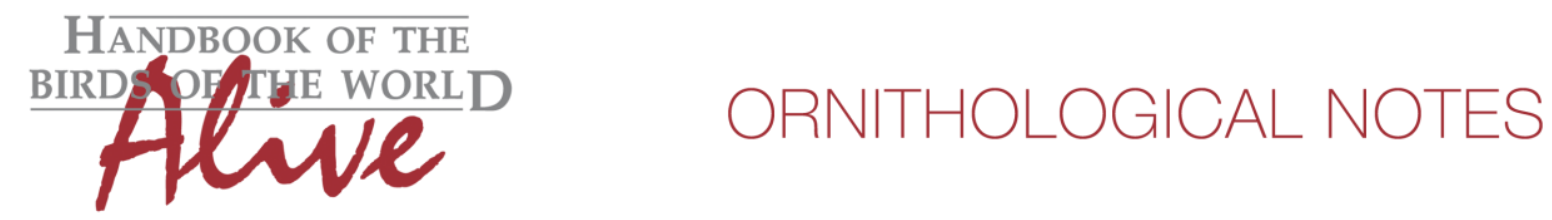

\section{A.d.consobrina}

4 recordings from $\mathrm{W}$ and $\mathrm{C}$ Bolivia presumably of this race are very similar to dorbignyi. Possibly on average lower-pitched with less high-pitched introductory notes (Fig. 2).

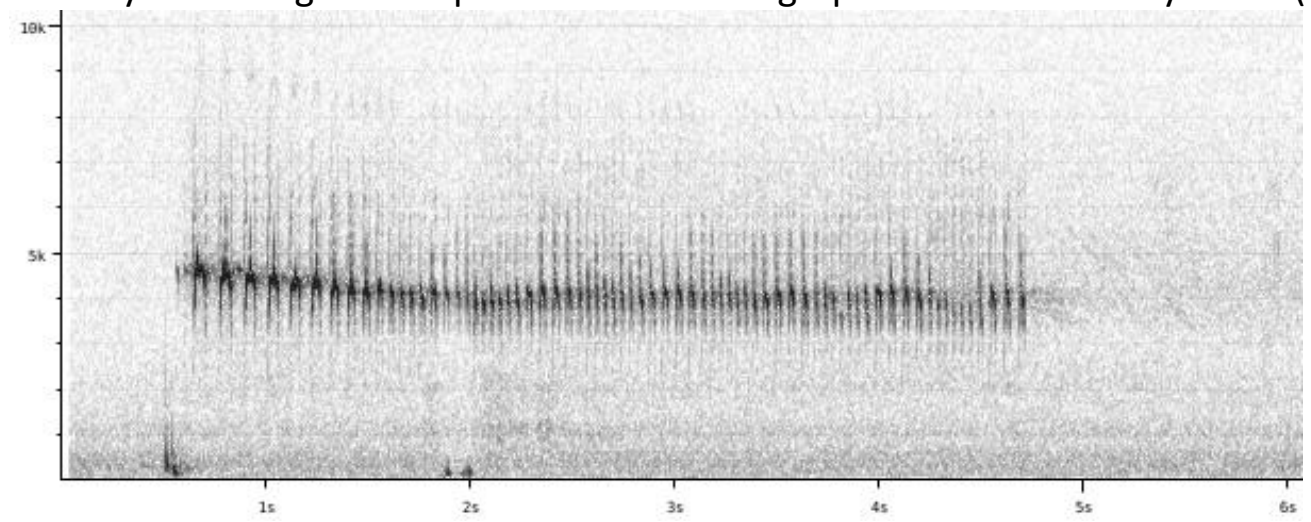

Figure 2: long song of consobrina

A.d.arequipae ( $n=6$, only recordings taken from $\mathrm{N}$ Chile and SW Peru)

Song is a trilled series of notes, typically abruptly shifting several times in pace and pitch. Often, a series of low-pitched longer overslurred notes is given within such a trilled song, with a quavering tonal quality (Fig. 3). Also, the song is often prolonged with additional shorter rattles. The song seems to lack an obvious pattern, such as in dorbignyi (= introductory notes accelerating into a trill). At least part of the notes in the song are nicely round overslurred notes with narrow frequency range and well-defined harmonics, a feature not seen in dorbignyi. Usually the base frequency of these notes is much lower than what could be defined as the center freq in the irregular notes of dorbignyi.

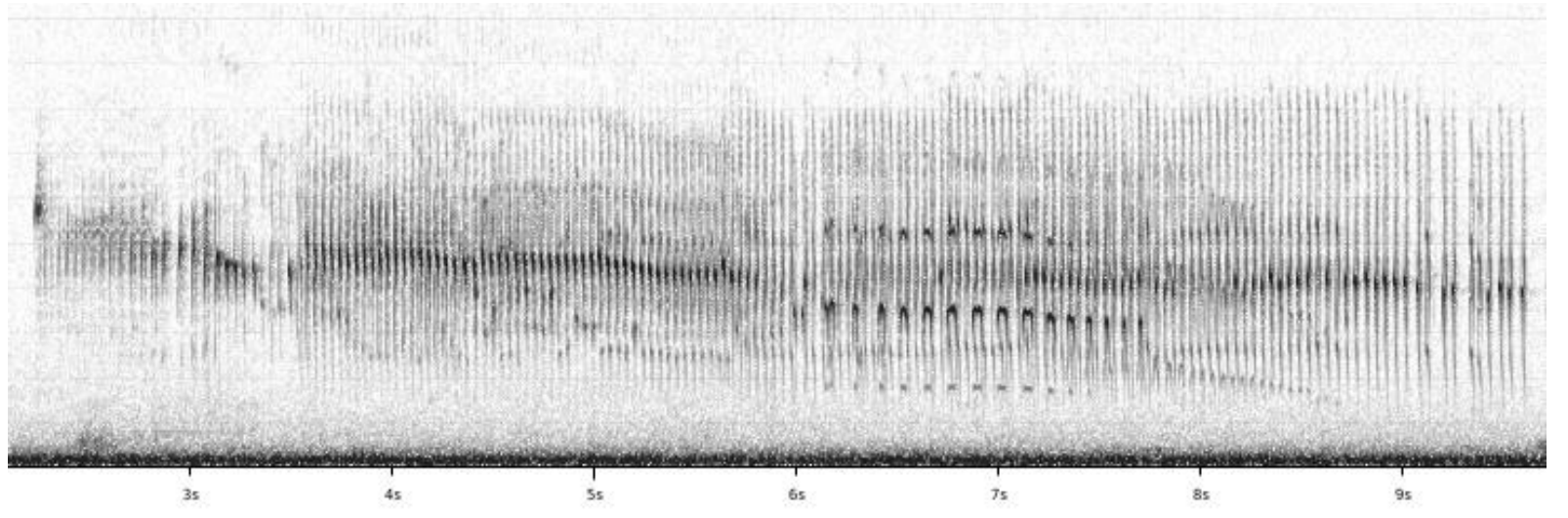

Figure 3: long song of arequipae

There are several recordings from around Nazca, lying outside the known region for arequipae, these are sometimes referred to as an undescribed taxon (pale iris, dull rump, less rufous in tail,..). These recordings all show the trilled nicely round overslurred notes as mentioned above. They do thus match rather well the recordings of 'true' arequipae. 


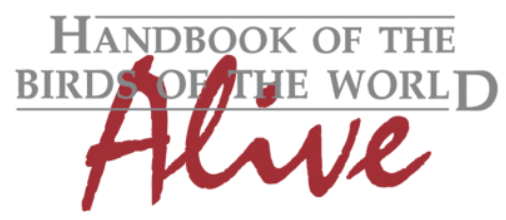

\section{ORNITHOLOGICAL NOTES}

\section{A.d.usheri}

$(n=5)$

Song is a short high-pitched trill at more or less even pitch, repeated at intervals. Notes accelerate slightly at first and slow down clearly towards the end. All notes have more or less the same shape, resulting in a monotonous-sounding trill (Fig. 4). Unlike arequipae, the song thus has a clear pattern, and song bouts repeated at intervals are very similar or identical.

$\begin{array}{ll}\text { length of song } & 1.2-2 \mathrm{~s} \\ \text { max freq of notes } & 8000-10500 \mathrm{~Hz} \\ \text { shortest note } & 0.02-0.03 \mathrm{~s} \\ \text { shortest pause } & 0.015-0.023 \mathrm{~s} \\ \text { longest note } & 0.03-0.04 \mathrm{~s}\end{array}$

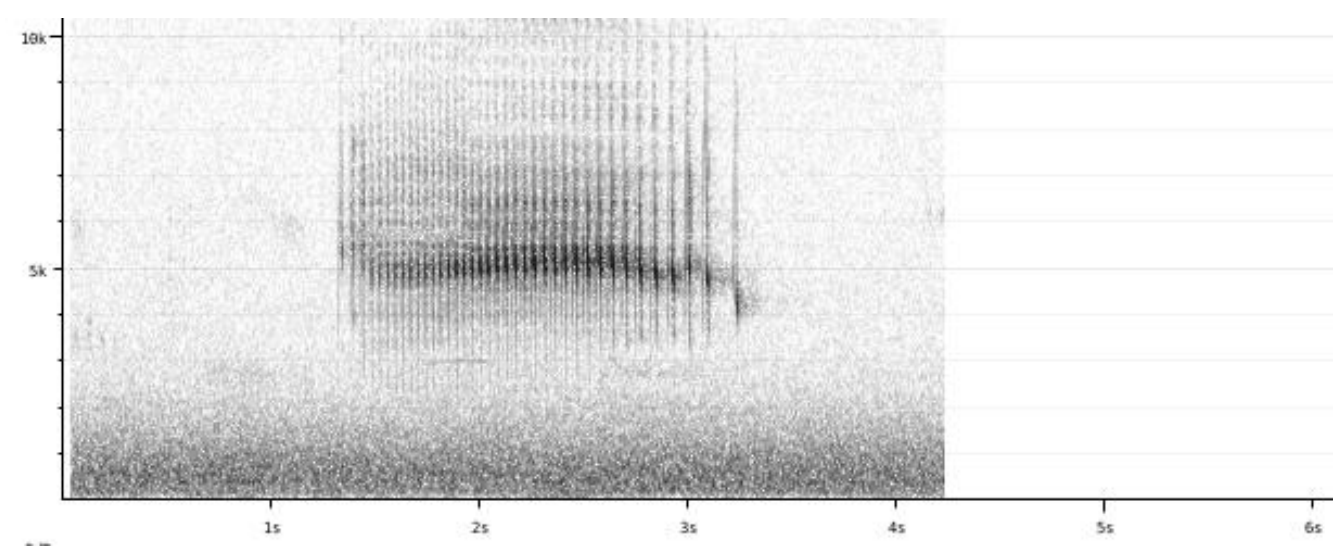

Figure 4: Song of usheri

\section{A.d.huancavelicae}

There seems to be only one recording of this race (XC31734). We assume here this is the typical song, but this obviously needs to be verified whenever more recordings become available.

Similar to usheri, song is a repeated trill. There are however clear differences (Fig. 5):

- the trill is longer in length

- the trill increases in pitch at first and decreases towards the end

- notes of the trill are lower pitched and longer in length

- note shape is curly, unlike the spiky conical shape of usheri

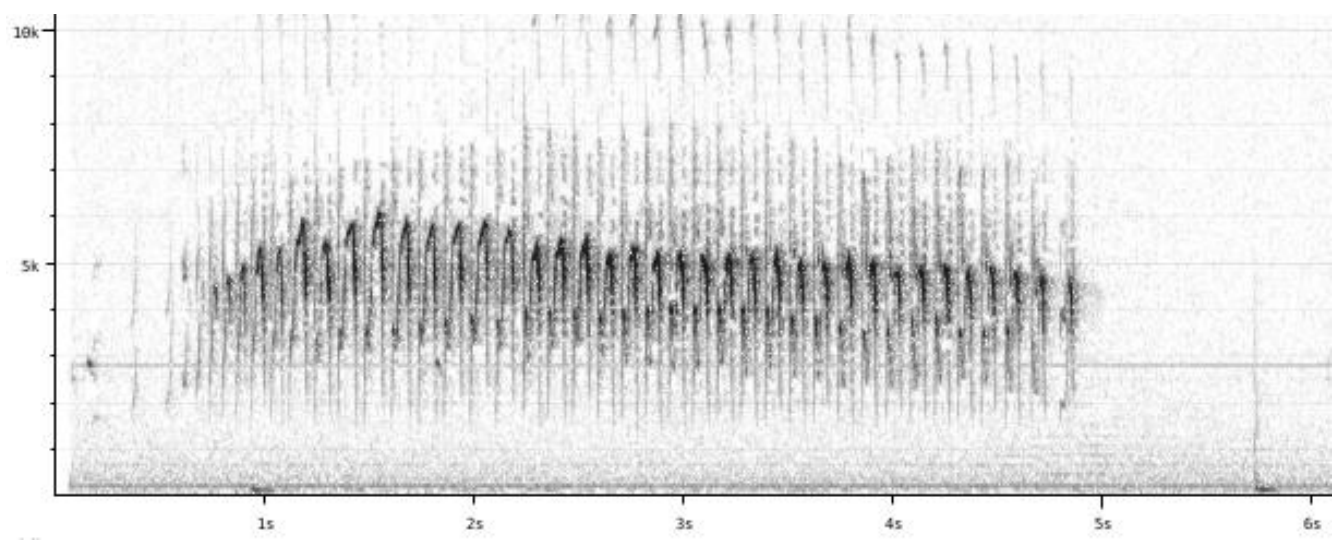

Figure 5: song of huancavelicae 

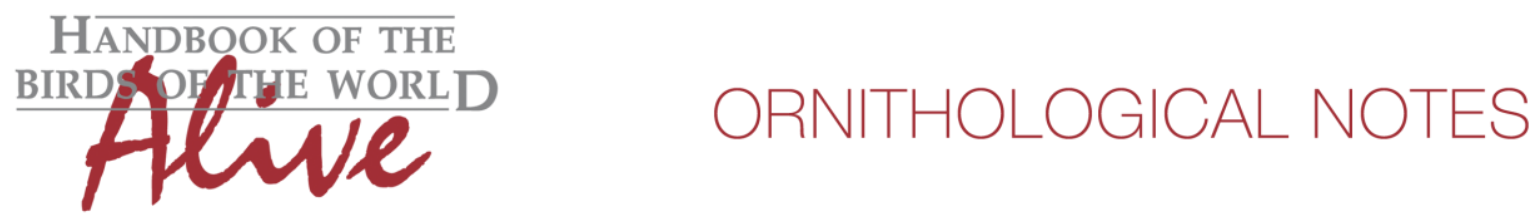

length of song

2.5-3.6s

max freq of notes

$5100 \mathrm{~Hz}$

shortest note

$0.035-0.04 \mathrm{~s}$

shortest pause

$0.03-0.035 \mathrm{~s}$

longest note

$0.075-0.09 \mathrm{~s}$

\section{A.d. ssp. nov.}

The race from Ancash (after 25 years apparently still undescribed... ) is documented quite well. ( $n=6)$ (rufous outer rectrices and rump, habitat,..)

Song is a series of well spaced notes gradually accelerating into a descending trill, or occasionally just a trill. At the end the trill sometimes slows down while fading and decreasing in pitch (Gig. 5). This is very similar to some songs of dorbignyi/consobrina. Possibly on average longer song and lower-pitched introductory notes

$\begin{array}{ll}\text { length of full song } & 3.4-5.3 \mathrm{~s} \text { (length of trill 1.9-5s) } \\ \text { highest center freq. } & 5500-6500 \mathrm{~Hz} \\ \text { shortest note } & 0.025-0.035 \mathrm{~s} \\ \text { shortest pause } & 0.02-0.04 \mathrm{~s} \\ \text { longest note } & 0.04-0.08 \mathrm{~s}\end{array}$

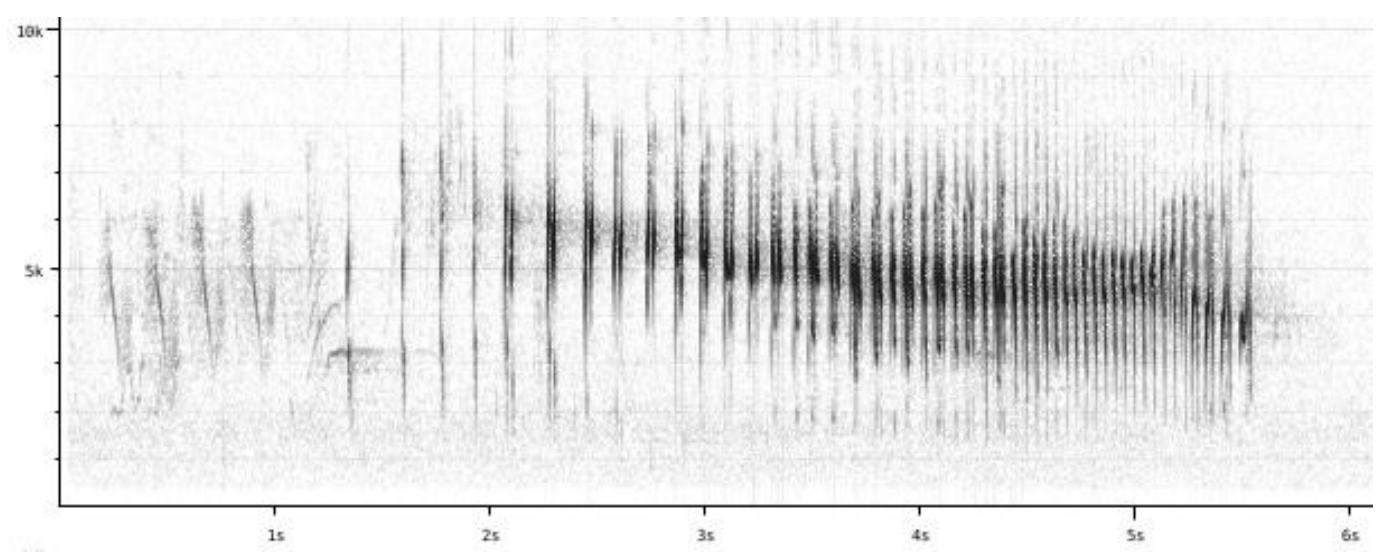

Figure 5: song of Ancash population

Vocal differences can be quantified as folllows:

\section{A.d.usheri vs. A.d.huancavelicae}

Both songs are structurally similar and thus comparison of main parameters is quite straightfoward. In huancavalicae the trill is longer in length (score 2), the trill increases in pitch at first and decreases towards the end (score 1), notes of the trill are lower pitched (score 2) and longer in length (score 3), note shape is curly, unlike the spiky conical shape of usheri. This leads to a total vocal score of 5 (with the remark that more recordings are needed of huancavelicae to confirm above differences!)

These two races differ from all others in only delivering a repeated monotonous trill. 

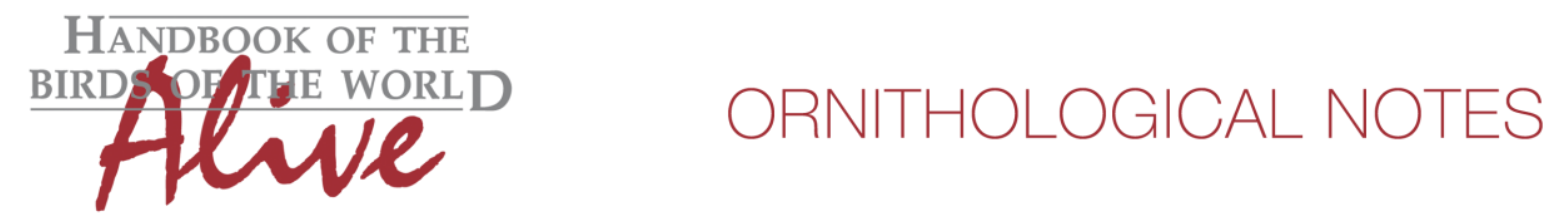

\section{A.d.arequipae}

Is the other race standing apart, because of its seemingly structureless song, with a wide variety of paces and pitches (3), and with unique fairly low-pitched rounded overslurred notes (2). Score vs. all other races 5.

dorbignyi group vs. A.d. ssp. nov. from Ancash

There is little difference in the song of these 2 groups, which is surprising as they occur geographically at the two extremes of this complex.

Possibly on average longer song and lower-pitched introductory notes, but a larger set would be needed to confirm this. A score of $1+1=2$ is thus a best estimation.

We have not included Berlepsch's Canastero A. berlepschi in this analysis. It's song is closest to the dorbignyi group (Fig. 6), scoring of vocal differences would probably give a score lower than when comparing dorbigny group vs arequipae, usheri and huancavelicae.

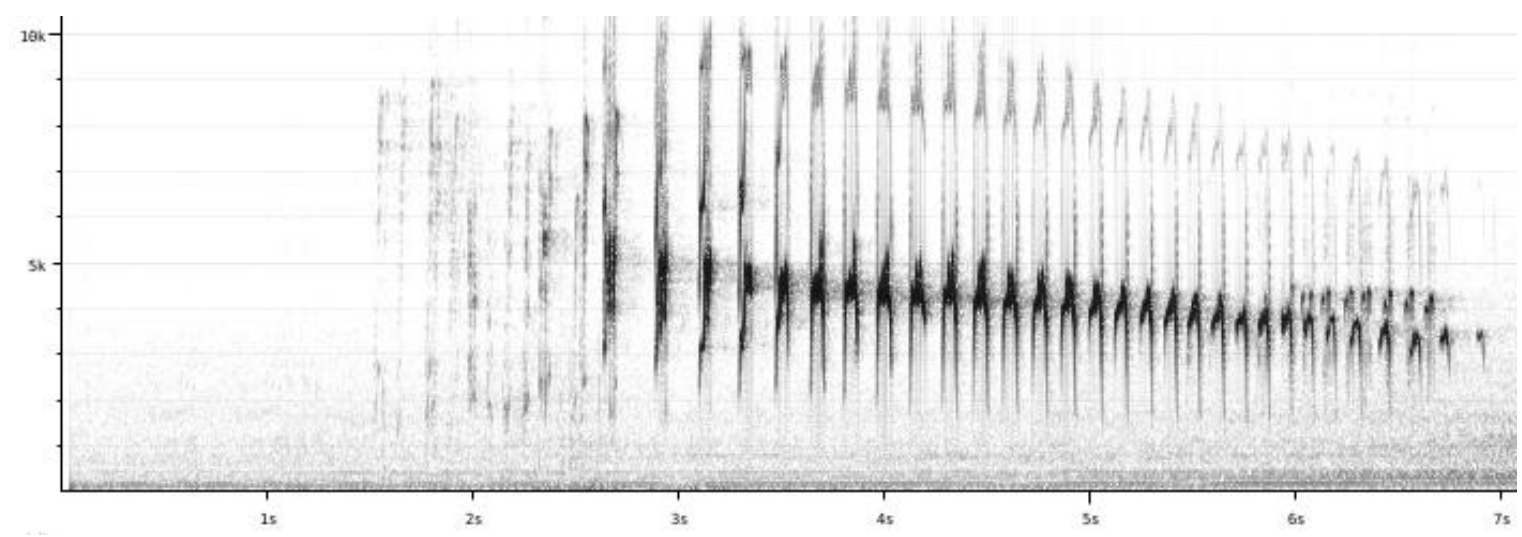

Figure 6: song of $A$. berlepschi

This note was finalized on 15th April 2015, using sound recordings available on-line at that moment. We would like to thank in particular the many sound recordists who placed their recordings for this species on XC.

\section{References}

Tobias, J.A., Seddon, N., Spottiswoode, C.N., Pilgrim, J.D., Fishpool, L.D.C. \& Collar, N.J. (2010). Quantitative criteria for species delimitation. Ibis 152(4): 724-746.

\section{Recommended citation}

Boesman, P. (2016). Notes on the vocalizations of Creamy-breasted Canastero (Asthenes dorbignyi). HBW Alive Ornithological Note 96. In: Handbook of the Birds of the World Alive. Lynx Edicions, Barcelona. (retrieved from http://www.hbw.com/node/932001 on 20 July 2016). 